\title{
Multitargeted Tyrosine Kinase Inhibitor JNJ-26483327
}

National Cancer Institute

\section{Source}

National Cancer Institute. Multitargeted Tyrosine Kinase Inhibitor/N1-26483327. NCI

Thesaurus. Code C77866.

An orally bioavailable, small-molecule, multitarg eted reversible tyrosine kinase inhibitor with potential antineoplastic activity. Multitargeted tyrosine kinase inhibitor JNJ-26483327 binds to and inhibits several members of the epidermal growth factor receptor (EGFR) family, including EGFR, HER2 and HER4; Src family kinases (Lyn, Yes, Fyn, Lck and Src); and vascular endothelial growth factor receptor type 3 (VEGFR3). By inhibiting several different signaling molecules that play crucial roles at various stages in tumorigenesis, this agent may inhibit tumor growth, invasion, migration and metastasis. In addition, JNJ26483327 crosses the blood-brain barrier (BBB). 